\title{
ENTREPRENEURIAL UNIVERSITY CONCEPT: CASE OF A DEVELOPING COUNTRY, ALBANIA
}

\author{
Bruna Papa ${ }^{1}$
}

\begin{abstract}
Today, the role of universities has changed and universities are not being only seen as creators and transmitters of knowledge but also as institutions that give innovative answers to economic and social challenges of society. The entrepreneurial university model is referred to many as the "Ideal state" of a university in responding efficiently and effectively to challenges and opportunities and being able to be competitive in today's environment of universities by fulfilling the university's "third mission". Even though many definitions exist for the concept of an entrepreneurial university, an overall common definition is lacking due to the fact that each institution follows a unique transformation path which is influenced by various economic and social factors of the environment they operate. The goal of this paper is to contribute to the understating of the above mentioned definition of an entrepreneurial university, how this concept is viewed in public higher education institutions in Albania and to identify which are the most important factors that might facilitate or serve as barriers for Higher Education Institutions (HEI-s) that might want to move towards this institutional approach. A questionnaire was distributed to academics in 5 higher public institutions in Albania and received 372 responses. An empirical study was conducted to contribute to the literature on the entrepreneurial university aspects with a specific focus on Albanian Higher Education Institutions. The results show that even in Albania, a common accepted definition is lacking. Factors such as cooperation with the private sector, appropriate reward systems, presence of role models and flexible structures are among the most important facilitators. While a lack of funding and inadequate links with the private sector are seen as the greatest barriers for public HEIs in Albania in becoming entrepreneurial institutions.
\end{abstract}

JEL Classification Numbers: I23, I28, L26; DOI: http://dx.doi.org/10.12955/cbup.v6.1185

Keywords: entrepreneurship, entrepreneurial university, barriers and facilitator components

\section{Introduction}

Today, role of universities has changed and universities are not being only seen as creators and transmitters of knowledge but also as institutions that give innovative answers to the economic and social challenges of society. Higher Education Institutions (HEI-s) are faced with various challenges such as: massification and wider access to disadvantaged students to higher education, wider access to research results, student and staff mobility, restriction of public funds, enhancement of graduate employment, closer links with the private sector and industry, how they are encouraging the creation of new firms and innovation in existing firms, how they are contributing to local and regional development, etc. How universities respond to these challenges is being judged by the society and sometimes they are subjected to pressures from various actors.

Beside their missions of teaching and conducting research, universities are undergoing to what is being called a second revolution, and are adding as part of their mission also the generation of social and economic values for their societies. Universities are being encouraged to find innovative solutions to face the challenges, pressures and trends in Higher Education. These innovative solutions are implying structural and administrative changes for HEIs. Apart from this an entrepreneurial culture is needed to be encouraged and developed inside the organization among its internal stakeholders (student and staff). Leadership plays an extremely important role in promoting an entrepreneurial spirit at all levels of the university. In order to respond effectively to the socio-economic demands of societies, HEIs need to have a diverse portfolio of their financial incomes. Academic entrepreneurship needs to be encouraged by incentives (both financial and non-financial) and universities need to offer support measures and effective infrastructure (as incubators, mentoring, patenting, licensing etc). A closer link with industry and government (Triple Helix Model) can contribute to a higher education institution moving toward an entrepreneurial approach faster. Research results (product and services) can be transferred outside the university through TTO-s (Technology Transfer Offices) and by commercializing their research results universities can increase their financial incomes.

Universities can react in various ways and approaches:

- They can adapt their internal procedures by being more efficient and altering the responsibilities between academics and administrators;

- They can engage in new forms of management "New Management" by adapting new structures and new administrative methods that require a deep change in culture,

\footnotetext{
${ }^{1}$ Faculty of Economy, University of Tirana, nickabruna@gmail.com
} 
commercialization of research products and services which is a more difficult approach that the first one;

- They can move toward a more extreme approach by adapting the model of an "Entrepreneurial University" in their universities culture, organizational form, daily operations and in managing the social capital of the HEI in relation to its stakeholders,

The entrepreneurial university model is referred to many as the "Ideal state" of a university in responding efficiently and effectively to challenges and opportunities and being able to be competitive in today's reality of universities. Many universities in developing countries are moving towards this model. Today, the third generation of university is the "entrepreneurial university" which is very important in the knowledge economy. This concept was developed in the 1980's describing the way universities can contribute to wealth creation and sustainable growth. Even though many attempts were done to define this concept, one single generally accepted definition is lacking due to the fact that each university has a unique transformation path within a given socio-economic context. The main objective of this paper is to contribute to the understanding of this concept by analyzing how public universities in Albania understand this phenomenon. Three research questions were raised in regard to the entrepreneurial university understanding in this paper:

Q1: What does it mean to be an entrepreneurial university?

Q2: Which are the factors that can serve as facilitators for a HEI in becoming entrepreneurial within the given socio-economic environment?

Q3: What are the factors that can serve as barriers for a HEI in becoming entrepreneurial within the given socio-economic environment?

The paper is organized into the 3 following sections: A literature review of the concept is presented in order to have a better understating of the phenomena, definitions of various authors and factors that can facilitate or hinder a university in becoming more entrepreneurial. The second section presents the methodology used in the study (who participated in the study, population of the sample, survey design). The third section presents the results of the survey on the 3 research questions presented above. The paper gives some conclusions on the definition, the facilitators and barriers of becoming an entrepreneurial university in the Albanian context and ends with the limitations and future research directions on the topic.

\section{Literature review of the concept}

1. Definition of the Entrepreneurial University

The literature framework on the concept of an entrepreneurial university presents various definitions. Various perspectives are presented by different authors (Table 1. Definition of the Entrepreneurial University) that define the concept by different point of views. Some see the entrepreneurial university as an institution that presents excellence in education and research. Etzkowitz (1983) sees the entrepreneurial university as an institution with a high number of financial sources (patents, research contracts, partnerships with private businesses, ect.) beside the traditional sources from public funding of government and students' fees. According to Dill (1998), an entrepreneurial university has formal units with explicit responsibility for promoting technology transfer.

An entrepreneurial university is associated with an university that has the capacity to produce innovation through research and new ideas (Shattock 2008). Gibb (2013) defines the entrepreneurial university as an institution that is designed to empower staff and students to demonstrate enterprise, innovation and creativity in research, teaching and pursuit and use of knowledge across boundaries.

Kirby (2002) sees the entrepreneurial university as one that has the ability to innovate, work in groups, exploit opportunities, take risks and effectively respond to the challenges they face. In a very competitive environment, entrepreneurial universities are the ones that will be able to survive by having clear strategies in showing excellence in teaching, research and entrepreneurship activities. Entrepreneurial universities seek to become "stand-up" universities that are significant actors in their own terms (Clark, 1998), offer and promote various support measures for entrepreneurial activities (Antoncic 2001) by working in close relationship with partners and networks with public and private institutions by investing in their social capital in order to facilitate the creation and exploitation of knowledge and technology (Leydesdorff and Meyer 2003). 
Despite all these views presented in Table 1 one common accepted definition is lacking this due to the fact that this field is still in its embryonic phase and each institution follows a unique transformation path which is influenced by various economic and social factors of the environment they operate.

\begin{tabular}{|c|c|c|}
\hline Year & Author & Definition \\
\hline 1983 & Etzkowitz & $\begin{array}{l}\text { "Universities that are considering new sources of funds like patents, research under by } \\
\text { contracts and entry into a partnership with a private enterprise }\end{array}$ \\
\hline 1995 & $\begin{array}{l}\text { Chrisman, Hynes } \\
\text { and Fraser }\end{array}$ & $\begin{array}{l}\text { The entrepreneurial university involves the creation of new business ventures by } \\
\text { university professors, technicians, or students }\end{array}$ \\
\hline 1995 & Dill & $\begin{array}{l}\text { University technology transfer is defined as formal efforts to capitalize upon university } \\
\text { research by bringing research outcomes to fruition as commercial ventures. Formal } \\
\text { efforts are in turn defined as organizational units with explicit responsibility for } \\
\text { promoting technology transfer }\end{array}$ \\
\hline 1998 & Clark & $\begin{array}{l}\text { An entrepreneurial university, on its own, seeks to innovate in how it goes to business. It } \\
\text { seeks to work out a substantial shift in organizational character so as to arrive at a more } \\
\text { promising posture for the future. Entrepreneurial universities seek to become "stand-up" } \\
\text { universities that are significant actors in their own terms. }\end{array}$ \\
\hline 1998 & Röpke & $\begin{array}{l}\text { An entrepreneurial university can mean three things: the university itself, as an } \\
\text { organization becomes entrepreneurial; the member of the university are turning } \\
\text { themselves somehow into entrepreneurs; and the interaction of the university with the } \\
\text { environment. }\end{array}$ \\
\hline 1999 & Subotzky & $\begin{array}{l}\text { The entrepreneurial university is characterized by close university-business partnerships, } \\
\text { by greater faculty responsibility for accessing external sources of funding, and by a } \\
\text { managerial ethos in institutional governance, leadership and planning. }\end{array}$ \\
\hline 2002 & Kirby & $\begin{array}{l}\text { As at the heart of any entrepreneurial culture, entrepreneurial universities have the ability } \\
\text { to innovate, recognize and create opportunities, work in teams, take risks and respond to } \\
\text { challenges. }\end{array}$ \\
\hline 2003 & Etzkowitz & $\begin{array}{l}\text { Just as the university trains individual students and sends them out into the world, the } \\
\text { entrepreneurial university is a natural incubator, providing support structures for teachers } \\
\text { and students to initiative new ventures: intellectual, commercial and conjoint. }\end{array}$ \\
\hline 2003 & $\begin{array}{l}\text { Jacob, Lundqvist } \\
\text { and Hellsmark }\end{array}$ & $\begin{array}{l}\text { An entrepreneurial university is based both commercialization (customs made further } \\
\text { education courses, consultancy services and extension activities) and commoditization } \\
\text { (patents, licensing or student owned star-ups. }\end{array}$ \\
\hline 2003 & Williams & ....is nothing more than a seller of services in the knowledge industry.... \\
\hline 2008 & Shattock & $\begin{array}{l}\text { Entrepreneurialism is a reflection both of institutional adaptiveness to a changing } \\
\text { environment and of the capacity of universities to produce innovation through research } \\
\text { and new ideas. }\end{array}$ \\
\hline 2011 & Salamzadeh & $\begin{array}{l}\text { "an entrepreneurial university is a dynamic system, which includes special inputs } \\
\text { (Resources, Rules and regulations, Structure, Mission, Entrepreneurial capabilities, and } \\
\text { Expectations of the society, industry, government and market.), processes (Teaching, } \\
\text { Research, Managerial processes, Logistical processes, Commercialization, Selection, } \\
\text { Funding and financial processes, Networking, Multilateral interaction, and Innovation, } \\
\text { research and development activities), outputs (Entrepreneur human resources, Effective } \\
\text { researches in line with the market needs, Innovations and inventions, Entrepreneurial } \\
\text { networks, and Entrepreneurial centers) and aims to mobilize all of its resources, abilities } \\
\text { and capabilities in order to fulfill its Third Mission" }\end{array}$ \\
\hline 2013 & Gibb & $\begin{array}{l}\text { Entrepreneurial higher education institutions are designed to empower staff and students } \\
\text { to demonstrate enterprise, innovation and creativity in research, teaching and pursuit and } \\
\text { use of knowledge across boundaries. They contribute effectively to the enhancement of } \\
\text { learning in a societal environment characterized by high levels of uncertainty and } \\
\text { complexity and they are dedicated to creating public value via a process of open } \\
\text { engagement, mutual learning, discovery and exchange with all stakeholders in society - } \\
\text { local, nationaland international." }\end{array}$ \\
\hline
\end{tabular}

\section{Facilitators and Barriers of an Entrepreneurial University}

There are many components that might serve as promoters and barriers for the development of an institution towards the "ideal state" of the entrepreneurial university.

\section{Supporting measures for Entrepreneurship}

The increase of entrepreneurial courses for student and staff stimulate the entrepreneurial culture within a university. Through academic entrepreneurship, student / staff can be presented with various projects that aim towards the preparation of business plans and the creation of new businesses, 
increase their abilities in identifying opportunities and taking risks and prepare them with the right entrepreneurial skills.

The development and implementation of such courses not only increases the possibility that they turn into potential entrepreneurs, but it also encourages a favorable attitude towards entrepreneurship for both staff and students. Thus, support measures for entrepreneurship have an influence on the human capital that serves as a determinant of the production functions according to the endogenous growth theories.

Close links with industry is another important component. In order to have a deeper interaction with industry and government it is very important to have organizational and governance structures that are quick in adapting and have the formal engagement of all stakeholders to a common vision. This helps promoting an entrepreneurial culture of the university, it shows commitment and identifies intrapreneurs inside the institution.

Effective structure and governance lead to greater engagement with the industry/government that contribute to the relationship between them in different stages of generation of products, science application and business start-ups. Thus, such engagement has an important influence in the creation of entrepreneurship capital and social capital that has an impact on the inversion attractiveness, it increases the number of new and existing enterprises and has implication on the national GDP and social benefits of the country they operate.

Role Models can have a great impact within universities in a positive way and can influence the entrepreneurial intentions of student. The organization of different activities, conferences and meetings in a university setting can serve as a great instrument to display informal influences of such entrepreneurial models (Venkataraman, 2004).

An incentives and reward system for staff at both an individual and team level (Miclea, 2004) should be taken into consideration and applied in order to stimulate and nurture entrepreneurship among the institution staff. Such rewards might take different forms starting from bonuses, reduced teaching load, profit-sharing, organizational recognition programs of the institution. Thus, the nurturing entrepreneurship has an impact in enhancing research talents, promoting academic entrepreneurs. It also has in influence on knowledge generation (high quality scientific papers) and knowledge transfer through patents, licenses and research contract that impacts not only human and social capital but at the same time knowledge capital. All the above have an impact in the mobility of staff (attraction of foreign researchers and exchange of local ones), internationalization of the institution and visibility in the international scientific community but at the same time it has a spillover effect with local and regional industries.

By using the Institutional Economics in entrepreneurship research (North, 2005) Urbano and Guerreo categorize the above mentioned component into formal and informal factors (Table 2).

Table 2: Formal and Informal Factors of an Entrepreneurial University (FF \&IF)

\begin{tabular}{|l|l|l|}
\hline & Formal Factor (FF) & Organizational and Governance structure \\
\cline { 2 - 3 } & FF & Supporting Measures for Entrepreneurship \\
\cline { 2 - 3 } & FF & Student and Staff Entrepreneurship Education \\
\cline { 2 - 3 } & Informal Factor (IF) & $\begin{array}{l}\text { Entrepreneurship Role models and Staff / Student } \\
\text { Reward Systems }\end{array}$ \\
\cline { 2 - 3 } & FF & Entrepreneurial Teaching Methodologies \\
\cline { 2 - 3 } & FF & University community \\
\cline { 2 - 3 } & IF & Attitudes towards Entrepreneurship \\
\hline Source: Urbano and Guerreo (2011)
\end{tabular}

\section{Data and Methodology:}

A questionnaire was distributed to 1807 academics and researches in 5 public higher educations in Albania. The universities that participated in the study were: the University of Tirana (UT), which is the biggest and oldest university in Albania; the Polytechnic University of Tirana (UPT) which is the biggest technical university in Albania, University "Ismail Qemali" in (UVL) Vlora, which is located in the south region of Albania, University "Luigj Gurakuqi" Shkodër(USH), which is located in the north region of Albania and University "Aleksandër Moisiu" Durrës (UAMD), which is the newest public 
university in Albania founded in 2006. The questionnaire was distributed online to 1807 academics and researchers in Albania that are part of the above mentioned institutions. We received 372 responses (127 UT, $41 \mathrm{UPT}, 107 \mathrm{UV}, 30 \mathrm{USH}, 67 \mathrm{UAMD}$ ), the margin of error is $4.5 \%$, confidence level at $95 \%$ $(\mathrm{z}=1.96, \mathrm{p}=\mathrm{q}=50 \%)$.

Taking into consideration the existing definitions identified in the literature of an entrepreneurial university, a survey was designed in order to see if there was a common consensus for this concept (Table 1 and Table 3) and how this concept is understood by academics in Albania. The questionnaire was designed in 3 parts based on the one used by Guerrero and Urbano (2011) (1-Entrepreneurial University definition; 2-Facilitating factors; 3-Barriers of being an entrepreneurial university). In the first part they were asked to choose one of the six definitions (presented in Table. 3) that according to them best described the concept of an entrepreneurial university. The participants also were asked to rank from 1 (the most) to 15 (the least) the factors that can facilitate a university in becoming more entrepreneurial. In the third part they were asked to rank from 1 (the most) to 12 (the least) the barriers that can hinder a university in becoming entrepreneurial.

Table 3: Which of the following best describes your understanding on an entrepreneurial university?

\begin{tabular}{|l|l|c|c|}
\hline & Definition & $\begin{array}{c}\text { Number of } \\
\text { respondents }\end{array}$ & Results in \% \\
\cline { 2 - 4 } & Chrisman (1995) & 8 & $2.2 \%$ \\
\cline { 2 - 4 } & Burton Clarck (1998) & 54 & $14.5 \%$ \\
\cline { 2 - 4 } & Ropke (1998) & 69 & $18.5 \%$ \\
\cline { 2 - 4 } & Kirby (2002) & 84 & $22.6 \%$ \\
\cline { 2 - 4 } & William (2003) & 32 & $8.6 \%$ \\
\cline { 2 - 4 } & Etzkowitz (2003) & 125 & $33.6 \%$ \\
\cline { 2 - 3 } & Total: & 372 & $100 \%$ \\
\hline \multicolumn{2}{|l|}{} \\
\hline \multicolumn{2}{|l|}{ Source: Author } \\
\hline
\end{tabular}

\section{Results and Discussion:}

\section{A perspective of Albanian HEIs on definition on an Entrepreneurial University:}

Figure 1 shows the results of how academics and researchers in Albania see the definition of the entrepreneurial university. Also, in Albania, a developing country, there isn't a common agreement regarding the definition of the entrepreneurial university. Almost $75 \%$ of the participants chose one of the 3 following perspectives.

$33.6 \%$ of the respondents agree on Etzkowitz's definition that an entrepreneurial higher education institution should serve as an incubator for its internal stakeholders (students and staff) that offer the right infrastructure to support new initiatives in creating start-ups.

Kirby's perspective was chosen by $22.6 \%$ of respondents that see the entrepreneurial university as an institution able to take risks, to exploit opportunities, to innovate and that has the ability to work in teams.

The definition of Ropke sees the entrepreneurial university as an organization that first of all is itself becoming entrepreneurial, its internal stakeholders turn into entrepreneurs and its cooperation with environment where it operates has an entrepreneurial model, was chosen by only $18.5 \%$ of respondents.

Sometimes, the nature of the university itself has an impact on what entrepreneurial university means for a higher education institution even in the same context. Figure 1 shows that the Polytechnic University of Tirana has a different nature than the other public universities in Albania, since it is a technical university, $44 \%$ of respondents have chosen Williams and Clarks definitions (Table1) where they see the entrepreneurial institution as a seller of services in the industry of knowledge and that plays an important role in the environment they operate and are quick in changing their organizational character to effectively adapt for the future.

Such results show that in the Albanian context, the academics and researchers see the entrepreneurial university concept as an institution that needs to offer the proper supporting infrastructure (business incubator, technology transfer offices, mentoring ect.) for their staff and students, that in a close interaction between the members within the university (through right and quickly adaptive organizational structure, effective and active communication system, stimulating initiatives etc.) and 
interaction and links with external stakeholders (Triple Helix Model), to have the ability to exploit opportunities, take risks, offer innovative solutions and answer challenges through commercial and intellectual entrepreneurship by having a socio-economic impact in the society they operate.

\section{Facilitators and Barriers}

Factors that facilitate universities in becoming more entrepreneurial:

In the Albanian context respondents identified that the most facilitating factors where, first of all, the cooperation with the private sector, followed by an appropriate reward system for the staff and those involved in promoting entrepreneurial activities. Having Role Models in entrepreneurship and assuring a flexible organizational structure and the right support for technology transfer were also among the most important factors in facilitating universities towards an entrepreneurial approach.

The attitude of students towards entrepreneurship and minimal regulation creation of new businesses were selected as less important factors that can facilitate universities in becoming more entrepreneurial.

Barriers that hinder universities in becoming more entrepreneurial:

For HEIs in Albania the results show that the most important barrier were the lack of financial resources, followed by an inappropriate reward system and inadequate links to the private sector.

Less important barriers selected by respondents were not being in accordance with research objectives and clashing with teaching objectives.

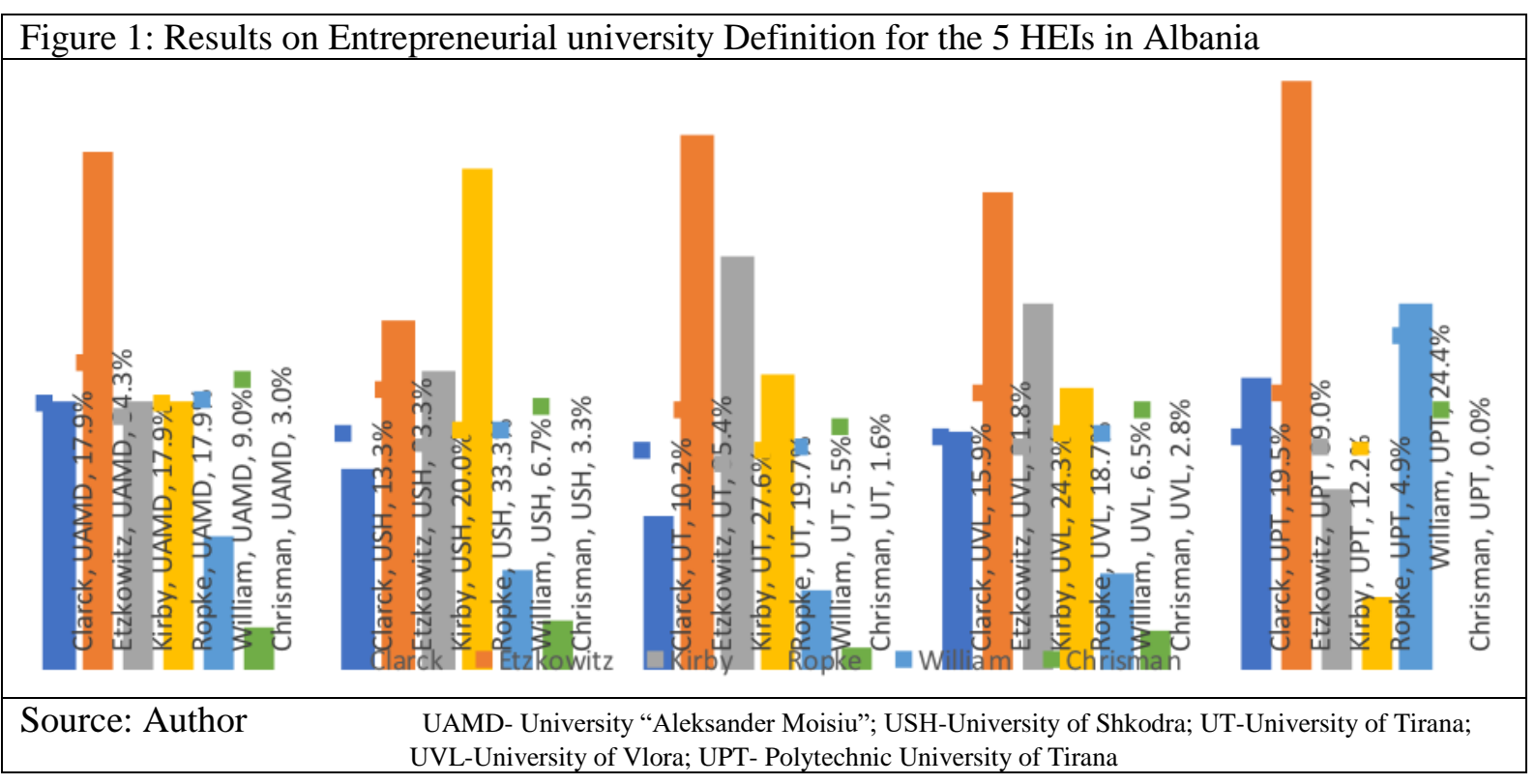

\section{Conclusions}

The results from this paper are important especially for those universities who understand the need of new ways to respond to the challenges they are facing and who are considering themselves becoming more entrepreneurial. The first step is to have a clear understanding of what being an entrepreneurial institution means to its own members in a given socio-economic environment. The definitions of the entrepreneurial university presented in Table 1 show various perspectives and roles of the university's stakeholders (internal /external) in approaching such model at the institutional level. Such diversity of viewpoints in the literature review is reflected also in the finding where even the most frequent perspective from Etzkowitz's (2003) was chosen by only 33.6\% of the respondents, following Kirby's view (22.6\%) and Ropke view (19\%), in Albanian public higher education institutions. University leadership and higher management should consider both formal and informal factors that are most important for their staff in facilitating their approaches toward an entrepreneurial model of their universities. From the other side a good understanding of what can hinder their efforts towards such model is crucial.

\section{Limitation of the study and Future Research Directions:}

Despite the results, the study has some limitations. The data we collected are based on subjective perceptions of academic staff of public universities. The survey was distributed only to academics from 
public HEIs and did not include private HEIs. In order to have a better understanding of such concept in the Albanian context all stakeholders need to be included, including academic staff, administrative staff, and students. Further studies might include external university stakeholders as well. Facilitators and Barriers identified that can facilitate or hinder a university in becoming more entrepreneurial can't be generalized to all HEIs in Albania as in private universities the findings can be different. Further research can be done by analyzing and exploring the Entrepreneurial University Dimensions of Albanian HEIs. However, being quite a new concept, the results and findings of the paper give an important starting point, especially to public universities, to start thinking about what being an entrepreneurial university means for their institutions and implementing new and innovative ways towards becoming entrepreneurial institutions.

\section{References}

Urbano.D and Guerrero.M (2013). Entrepreneurial Universities: Socio Economic Impacts of Academic Entrepreneurship in European Region“, Economic Development Quartely 2013, page 43;

David.A Kirby, Guerrero.M and Urbano.D (2011), Making Universities more Entrepreneurial: development of a Model, Canadian Journal of Administrative Sciences;

Alvarez.C and Urbano. D (2014), Insitutional Dimensions and entrepreneurial university: An international Study, Springer Science and Business Media New York;

OECD (2012), A guiding Framework for Entrepreneurial Universities, final version;

Clark.B (1998): Entrepreneurial Pathways of Universities Transformation, Creating Entrepeneurial Universities, Paris and Oxford, IAU and Elsevier Science;

Ropke. J (1998) The entrepreneurial university, innovation, academic knowledge creation and regional development in a globalized economy, Working paper, Economics Department, Philips University, Marburg, Germany;

Sporn.B ( 1998), Building adaptive universities: Emerging organisational forms based on experiences of European and US universities. Tertiary Education and Management;

David. A Kirby, (2004), Creating entrepreneurial universities in the UK: Applying entrepreneurship theory to practice. Journal of Technology Transfer, 599-603.

Urbano, D Guerrero. M and Kirby. D (2006). A literature review on entrepreneurial universities: An institutional approach. Business Economics Department. Autonomous University of Barcelona

Arnaut.D (2013). Towards an Entrepreneurial University;

Salamzadeh.A, Imanipour.N, Farsi.Y, (2013), Entrepreneurial University Conceptualization: Case of Developing Countries;

Fayolle.A, Redford.T.D (2014) - HandBook and Entrepreneurial University;

Gibb.A, Hofer.R.A and Klofsten.M (2013), The entrepreneurial higher education institution a review of the concept and its relevance today;

Audretsch.B (2014). From the entrepreneurial university to the university for the entrepreneurial society, Journal of Technology Transfer, Volume 39;

EULP (201), The Entrepreneurial University: From concept to Action;

Thorp.H and Goldstein.B (2010), The Entrepreneurial University, Inside Higher Education. 